\title{
Políticas da Terra: Existe um novo discurso ambiental pós Rio +20?
}

\author{
Policies on the Earth: Is there a new environmental discourse after the Rio $+20 ?$
}

\author{
Juliana Wenceslau ${ }^{1}$ \\ Natalia Latino Antezana ${ }^{2}$ \\ Paulo du Pin Calmon ${ }^{3}$
}

\section{Resumo}

Políticas públicas envolvem a construção de significado através de discursos, que caracterizam redes semânticas complexas, articulando diferentes pressupostos, conceitos e hipóteses. O objetivo deste artigo é contribuir para o debate sobre a evolução recente da política ambiental, indagando em que medida os debates que marcaram a Rio +20 caracterizam uma ruptura com os quatro discursos predominantes na política ambiental ao longo dos últimos 40 anos. São eles: sobrevivencialismo, resolução de problemas, sustentabilidade e radicalismo verde. Esses discursos são diferentes em seus pressupostos ontológicos (mais realista ou mais nominalista); nas suposições sobre a natureza dos relacionamentos com o meio ambiente (baseados em competição ou em cooperação); na perspectiva que assumem sobre os atores (individualistas ou coletivistas; fortes ou fracos); e nas metáforas que utilizam para defender seus pontos de vista (DRYZEK, 1997). Algumas perguntas também são colocadas para avaliar o impacto e plausibilidade do discurso: que política é associada a ele; seu efeito nas políticas públicas e nas instituições; os argumentos dos críticos; e as falhas reveladas pelas evidências e argumentos. A análise do discurso da Rio +20 foi baseada no documento final da conferência "The Future We Want". Concluímos que os debates da conferência agregam dois grandes discursos: resolução de problemas e sustentabilidade. Alguns efeitos antecipados da Rio +20 são: a melhoria das estatísticas ambientais; aumento de empregos ligados à economia verde; e adoção de políticas regulatórias que modifiquem os preços relativos do uso dos recursos e internalizem os custos das externalidades ambientais.

Palavras-chave: Discurso ambiental. Rio +20. Política ambiental. Desenvolvimento sustentável. Economia verde.

\section{Abstract}

Public policy involves the search for meaning through discourses that are complex semantic systems, expressing different perspectives, concepts and assumptions. This paper aims to contribute to the current dialogue concerning recent environmental policies, inquiring as to what extent the debates that took place at Rio +20 break away from the dominant environmental discourses of the last 40 years. These predominant discourses are: survivalism, problem solving, sustainability and green radicalism. They differ on their ontology (realist or nominalist), their assumptions

Artigo submetido em 30 de julho de 2012 e aceito para publicação em 09 de agosto de 2012.

1 Doutoranda em Administração Pública pelo Programa de Pós-Graduação em Administração - PPGA da Universidade de Brasília; Mestre em Políticas Públicas pela London School of Economics. Endereço: SQN 212 BI A apt. 310, Asa Norte, CEP 70861-010, Brasília-DF. E-mail: juwenceslau@uol.com.br

2

Mestranda em Administração Pública pelo Programa de Pós-Graduação em Administração - PPGA da Universidade de Brasília. Endereço: Universidade de Brasília - Campus Darcy Ribeiro, PPGA - Instituto Central de Ciências, ala norte, subsolo, módulo 25, CEP 70910-900, Brasília-DF. E-mail: natalialatino@gmail.com

PhD pela University of Texas at Austin, MA pela Vanderbilt University; Professor Adjunto do Instituto de Ciência Política e do Programa de Pós-Graduação em Administração - PPGA da Universidade de Brasília. Endereço: SHCGN 713 BI P apt. 201, Asa Norte, CEP 70760-746, Brasília-DF. E-mail: paulocalmon@uol.com.br 
regarding natural relationships (competition or cooperation), agents and their mot ives (individuals or collectivities, strong or weak) and the key metaphors and other rhetorical devices used to defend their positions (DRYZEK, 1997). Some questions are also asked in order to evaluate the impact and feasibility of the discourse: policies associated with discourse, effect on the policy of governments, the effect on institutions, arguments of critics and flaws revealed by evidence and argument. These analytical devices were applied to the final document of the conference "The Future We Want" to appraise the Rio +20 discourse. We conclude that two prior discourses can be included in the conference debates: problem solving and sustainability. Some anticipated effects of Rio +20 are: improvement of environmental statistics; increased number of green economy jobs; and public policies that change the relative prices of using natural resources and internalizing the costs of environmental externalities.

Keywords: Environmental discourse. Rio +20. Environmental policy. Sustainable development. Green economy.

\section{Políticas da Terra: Existe um novo discurso ambiental pós Rio +20?}

Ao longo dos últimos anos tem ocorrido uma crescente ênfase no estudo da dinâmica e das propriedades dos discursos que pautam as políticas públicas. Tal ênfase decorre, entre outros elementos, do reconhecimento de que muitos dos temas mais importantes na agenda governamental são complexos e envolvidos em grande incerteza e ambiguidade e, portanto, nem sempre podem ser analisados simplesmente com base em evidências ou, se essas evidências existem, elas são objeto de contestação e disputas políticas. Nesse sentido, a análise de políticas públicas passa a acompanhar tendência importante já presente nas Ciências Sociais em geral, que reconhece nos discursos, na análise crítica e no mundo das ideias um conjunto de elementos fundamentais importante para entender a dinâmica social e política das decisões governamentais (FOUCAULT, 1980; HABERMAS, 1998; HALL, 2001; SKOCPOL, 1985; MARCH, 2010).

Políticas públicas envolvem a construção de significado através de discursos, que caracterizam redes semânticas complexas, articulando diferentes pressupostos, conceitos e hipóteses sobre como e quando atuar nos problemas que se apresentam. Diferentes discursos geram diferentes diagnósticos e suscitam diferentes formas de problematizar uma situação assim como demandam o uso de diferentes instrumentos e medidas de políticas públicas.

O objetivo deste artigo é contribuir para o debate sobre a evolução recente da política ambiental, indagando em que medida os debates que marcaram a Rio + 20 caracterizam uma ruptura com os discursos que prevaleceram no âmbito da política ambiental até então. Afinal de contas, qual foi o impacto da Rio +20 para os debates recentes sobre política ambiental? No campo das ideias e dos discursos, que inovações importantes foram propostas?

O ponto de partida do artigo é a existência de quatro grandes discursos que têm marcado o debate sobre política ambiental ao longo dos últimos quarenta anos. São eles: sobrevivencialismo, resolução de problemas, sustentabilidade e radicalismo verde, que se distinguem em seus pressupostos ontológicos. A existência desses quatro discursos ambientais básicos foi proposta por Dryzek (1997) e representa, de maneira bastante adequada, a evolução do debate no período anterior à Rio +20 . Esses discursos são diferentes nos pressupostos sobre a natureza dos relacionamentos com o meio ambiente (baseados em competição ou em cooperação); na perspectiva que assumem sobre os atores (coletivistas ou individualistas; fortes ou fracos); e nas metáforas que seus subscritores utilizam para defender seus pontos de vista.

Com objetivo de caracterizar a evolução recente dos discursos ambientais, esse artigo está estruturado da seguinte forma: inicialmente será apresentada a metodologia da análise de discurso e sua aplicação ao debate ambiental. Em seguida, serão detalhados os principais discursos ambientais até 2012, especificamente: resolução de problemas, sobrevivencialismo, sustentabilidade e radicalismo verde. Por fim, será feita a análise do discurso do documento final da Rio +20 , procurando-se avaliar se ele traz novidades ao tema, ou se é uma combinação de discursos preexistentes. Também serão analisados os documentos produzidos nos 
eventos paralelos à Rio +20 , como a Cúpula dos Povos, a Cúpula dos Prefeitos e a Cúpula das Mulheres Chefes de Estado. Na conclusão, o trabalho procura refletir sobre as perspectivas futuras das políticas ambientais após a realização da Rio +20 , utilizando a análise do documento final da Conferência "The Future We Want" (UNITED NATIONS, 2012) para pensar sobre o efeito nas políticas governamentais e nas instituições, os argumentos dos críticos e as possíveis falhas reveladas pelas evidências e argumentos.

\section{Análise de Discurso: A Complexidade Ambiental e a Proliferação de Problemas}

A abordagem metodológica de análise de discurso leva em conta a história bem como o conteúdo do discurso. $\mathrm{O}$ modo de pensar sobre conceitos a respeito de um determinado tema pode mudar dramaticamente ao longo do tempo, com consequências políticas e para as políticas públicas. O discurso é uma visão de mundo compartilhada que é transmitida pela linguagem, permitindo àqueles que a partilham interpretar informações por meio de narrativas históricas. Cada discurso tem pressupostos que são ponto de partida para análise, debates, consensos e disputas. Eles possibilitam que histórias sejam contadas de acordo com a interpretação que se deseja defender. Há elementos comuns aos discursos que servem para analisar seus conteúdos e seus efeitos. Devem ser trabalhados quatro elementos para analisar um discurso (DRYZEK, 1997, p. 15-18):

\section{Ontologia: entes fundamentais reconhecidos ou construídos pelo discurso}

Os discursos focalizam temas específicos que estão ao nosso redor. Assim, alguns discursos reconhecem a existência de ecossistemas, outros veem a natureza como matéria bruta, outros ainda focalizam a perniciosidade da ação humana. A variedade dos discursos está baseada no modo como veem a organização do mundo também. Assim, alguns discursos entendem a humanidade como categoria geral. Outros dividem a humanidade em grupos sociais, políticos, geográficos, étnicos, tais como governos, setor privado, mulheres, indígenas etc.

\section{Hipóteses sobre relações naturais}

Todos os discursos desenvolvem hipóteses sobre as relações entre os entes fundamentais, tanto dos sistemas naturais quanto dos sistemas sociais humanos. Alguns entendem que as relações são competitivas; outros, que são cooperativas. Nas visões competitivas, podem ser utilizados mercados para caracterizar os sistemas sociais onde há disputas por recursos escassos. A competição pode fundamentarse em hierarquias sociais, como a dominação baseada em gênero, raça, poder econômico, expertise, etc.

\section{Agentes e seus motivos}

A história requer atores, que podem ser indivíduos ou coletividades. Geralmente, há juízos de valor em relação à ação dos atores. Um discurso pode ver os servidores públicos como administradores bemintencionados com espírito público. Outro pode enxergá-los como burocratas autointeressados em conluio com capitalistas que visam a lucros apenas. Outros podem ignorar a existência dos funcionários governamentais. Assim, há dezenas de atores (elites, consumidores, empresários) que são classificados de formas díspares (ignorantes, virtuosos, desinteressados, ativistas) a cada discurso.

\section{Metáforas e outros mecanismos retóricos}

Metáforas são ferramentas retóricas utilizadas para convencer o interlocutor, utilizando-se de imagens (no caso dos discursos ambientais têm sido utilizadas alusões a Gaia, deusa-mãe, nave espacial, organismos vivos,) ou apelando-se para práticas e direitos amplamente aceitos (liberdades, declarações universais, convenções internacionais). 


\section{Quadro 1}

\section{Elementos para a Análise do Discurso}

1. Entes fundamentais reconhecidos ou constituídos pelo discurso (ontologia);

2. Hipóteses sobre relações naturais;

3. Agentes e suas motivações;

4. Metáforas e outros mecanismos retóricos.

Fonte: Dryzek, 1997, p. 18.

Os impactos dos discursos podem ser sentidos nas políticas dos governos, dos organismos internacionais e suas instituições. A torrencial criação de legislações ambientais dos anos 70 nos países industrializados é um exemplo dos efeitos do discurso resolução de problemas, na subcategoria racionalismo administrativo. Os discursos muitas vezes são instituições informais que proporcionam o entendimento de contextos no qual acontecem as interações sociais, em paralelo às instituições formais. Por exemplo, o radicalismo verde influenciou comunidades a se distanciarem do governo e do capitalismo corporativo, buscando soluções alternativas de autossuficiência.

A análise do discurso também requer atenção às disputas e interações que ocorrem entre os adeptos e seus críticos, suas promessas, ameaças e implicações práticas para a política e políticas públicas. Ela possibilita que falhas nos argumentos sejam encontradas, bem como complementaridades e similaridades. Algumas perguntas são colocadas para avaliar o impacto, plausibilidade e atratividade do discurso (ver Quadro 2).

Quadro 2

Itens para avaliar os Efeitos do Discurso
1. A política associada ao discurso
2. Efeito nas políticas públicas dos governos
3. Efeitos nas instituições
4. Argumentos dos críticos
5. Falhas reveladas pelas evidências e argumentos

Fonte: Dryzek, 1997, p. 20.

Com intuito de caracterizar e comparar o discurso da Rio +20 e seus possíveis efeitos na política dos governos, políticas públicas e instituições, será analisado o conteúdo do documento "The Future We Want" (UNITED NATIONS, 2012). Porém, inicialmente será feito o resgate histórico dos discursos ambientais.

\section{Trajetória Histórica dos Discursos Ambientais}

A preocupação ambiental é um tema recente na agenda governamental. Na maioria dos países, foi ao final da década de 1960 que a preocupação com o meio ambiente ganhou notoriedade, vigorando a visão de que os recursos do planeta são finitos, e que o ritmo de crescimento econômico e demográfico levaria a uma situação catastrófica, sendo urgente a necessidade de medidas para retroceder esse quadro (DRYZEK, 1997). 
Ao longo dessas quatro décadas de discussões sobre o meio ambiente, surgiram vários argumentos que tornaram o debate multipolar, com avanços e recuos. Isso acontece porque os problemas ambientais são interconectados, multidimensionais e podem ser estudados e compreendidos a partir de distintas perspectivas (DRYZEK, 1997). Assim, enquanto alguns defendem que a vida na Terra está ameaçada pela ação humana e pelas mudanças climáticas dela provenientes, outros defendem que as mudanças climáticas são fenômenos naturais sobre os quais a ação humana possui efeitos muito pequenos quando comparada a outros fatores naturais; enquanto sobrevivencialistas e os adeptos do radicalismo verde defendem que os recursos naturais são finitos, outros, como os adeptos ao discurso de Prometeu, acreditam que não há necessidade de preocupação em relação aos limites do meio ambiente. Existe ainda a tese de que o mundo estaria passando por um processo de resfriamento e de que o aquecimento global seria apenas uma tentativa dos países ricos de frear o crescimento dos países em desenvolvimento (RANGEL, 2007 apud CARVALHO, MACHADO e MEIRELLES, 2011).

Nesse contexto, diante de um tema tão interconectado e multidimensional, Dryzek (1997) delineia dois níveis de complexidade - a complexidade dos ecossistemas e dos sistemas sociais humanos - e acrescenta: "the more complex a situation, the larger is the number of plausible perspectives upon it" (DRYZEK, 1997, p. 8), fazendo referência ao nível de ambiguidade da temática ambiental, em que muitas vezes não existe o certo ou o errado, mas apenas interpretações distintas acerca de um mesmo fenômeno.

\section{Sobrevivencialismo}

A visão de mundo dos sobrevivencialistas defende que as demandas humanas necessitam ser controladas, pois a Terra possui capacidade finita para atender a essas demandas, e que medidas draconianas necessitam ser estabelecidas como forma de limitar a ação humana (DRYZEK, 1997). O discurso é fundamentado numa ontologia nominalista, pela qual o meio ambiente é um estoque de recursos não renováveis. $\mathrm{O}$ discurso surgiu em 1968, a partir da primeira fotografia da Terra tirada do espaço. Essa imagem ganhou mais repercussão pela hipótese Gaia, segundo a qual a Terra se comporta como se fosse um único organismo (LOVELOCK, 2010). Dessa forma, a metáfora de Gaia se tornou um recurso muito utilizado pelos defensores do discurso sobrevivencialista.

As relações naturais são guiadas pela hierarquia: existe o pressuposto de que as elites são responsáveis pelo mundo, seja pela expertise, pelo carisma ou por ambos os fatores. Assim, toda a ação relativa às decisões sobre o futuro do meio ambiente cabe às elites; a população não age nesse sentido, ela é apenas monitorada e controlada de acordo com as definições feitas pelas elites. Estas, por sua vez, agem com base em seus interesses e suas motivações se mantêm em disputa. Em termos de metáforas e de outros mecanismos retóricos, são utilizadas as ideias de colapso; a analogia com uma nave-mãe que necessita de sistemas de suporte que garantam a vida de sua população; a comparação do crescimento da população e dos prejuízos causados ao meio ambiente pelo homem com um câncer que o planeta precisa tratar, entre outros. Cabe citar também a comparação da Terra com um vilarejo medieval, metáfora lançada pelo ensaio "A Tragédia dos Comuns", de Garrett Hardin (1968), segundo a qual os interesses privados são opostos aos interesses comuns, sendo que o meio ambiente, como interesse comum, geralmente será posto de lado em razão de interesses privados.

Em 1970, as ideias de Paul Ehrlich ganharam espaço com a publicação do livro "The Population Bomb”, segundo o qual muitas pessoas morreriam de fome durante os anos 70 e 80 devido à superpopulação. $\mathrm{O}$ autor, assim como muitos outros sobrevivencialistas, fazia prescrições centralizadoras e autoritárias, em particular, o estabelecimento de limites ao crescimento populacional.

Nesse contexto, aconteceu a primeira Conferência das Nações Unidas sobre o Meio Ambiente Humano, realizada na cidade de Estocolmo em 1972. O evento representou o primeiro grande passo no enfrentamento dos problemas ambientais e institucionalizou a temática ambiental na agenda política internacional. Nessa 
ocasião, foram estabelecidos o Dia Mundial do Meio Ambiente (5 de junho) e os princípios que até hoje norteiam a política ambiental da maioria dos países, dentre os quais: a obrigação do homem de proteger e melhorar o meio ambiente, para as gerações presentes e futuras; manter e, sempre que possível, restaurar ou melhorar a capacidade da Terra de produzir recursos renováveis vitais; assegurar o usufruto dos recursos não renováveis da Terra, bem como evitar o perigo do seu esgotamento; a ideia de que as políticas ambientais devem melhorar e não afetar adversamente o potencial desenvolvimentista atual e futuro dos países em desenvolvimento; e o progresso da ciência e da tecnologia para contribuir para o desenvolvimento econômico, social e ambiental (UNITED NATIONS, 1972). O livro "The Limits to Growth" de Meadows, Meadows, Behrens e Randers (1972 apud DRYZEK, 1997), publicado no mesmo ano, também influenciou significativamente o discurso ambiental.

Em oposição ao discurso do sobrevivencialismo, está o discurso de Prometeu, segundo o qual não existe a necessidade de haver preocupações quanto aos limites dos recursos naturais: o crescimento econômico e o desenvolvimento de novas tecnologias conseguem criar alternativas de recursos, por meio de relações de equilíbrio entre demanda e oferta. A posição ontológica do discurso de Prometeu é a de que os recursos naturais não existem; não existe um estoque de recursos, quando eles se tornarem necessários, eles vão ser procurados e encontrados (SIMON, 1981 apud DRYZEK, 1997). As entidades básicas do discurso de Prometeu são as pessoas, os mercados, os preços, a energia e a tecnologia, que se relacionam de acordo com a lógica de que as mentes humanas possuem hierarquia sobre todo o sistema. Nesse caso, a capacidade de ação não está restrita a uma elite, mas acessível a todos. Assim, as pessoas são vistas como solucionadoras de problemas, não como a causa deles, e agem motivadas por interesses materiais próprios. A principal metáfora utilizada por essa categoria discursiva é a da máquina, remetendo ao desenvolvimento de tecnologias, criação de recursos e conserto de disfunções no ambiente. O discurso de Prometeu teve grande influência durante a década de 80, sendo que Dryzek (1997) enfatiza sua predominância no discurso político da administração de Reagan (de 1981 a 1989, com dois mandatos consecutivos), o que serve para explicar os posicionamentos dos Estados Unidos nas negociações internacionais do período.

\section{Quadro 3}

\section{Análise do Discurso: Sobrevivencialismo e a Resposta de Prometeu}

\begin{tabular}{|l|l|l|l|}
\hline \multicolumn{1}{|c|}{ Ontologia } & \multicolumn{1}{|c|}{$\begin{array}{c}\text { Hipóteses sobre } \\
\text { relações naturais }\end{array}$} & Agentes e Motivações & \multicolumn{2}{c|}{ Metáforas } \\
\hline \multicolumn{3}{|c|}{ Sobrevivencialismo } & Colapso \\
$\begin{array}{l}\text { Carrying Capacity } \\
\text { População máxima que } \\
\text { um ecossistema suporta, } \\
\text { limites ecológicos, } \\
\text { tragédia dos comuns, } \\
\text { estoque finito de } \\
\text { recursos, população } \\
\text { como um agregado }\end{array}$ & $\begin{array}{l}\text { Hierarquia baseada na } \\
\text { cidadãos, controle dos } \\
\text { agregados como } \\
\text { população, recursos, } \\
\text { poluição }\end{array}$ & $\begin{array}{l}\text { A elite pode operar de } \\
\text { acordo com seus } \\
\text { interesses, seja para } \\
\text { maximizar o crescimento } \\
\text { econômico com justiça } \\
\text { social, ou controlar o } \\
\text { crescimento com ação } \\
\text { coordenada global. A } \\
\text { população não age, é } \\
\text { controlada pelas } \\
\text { estatísticas }\end{array}$ & Taia, casa, sistema \\
\hline
\end{tabular}


Continuação do quadro 3

\begin{tabular}{|c|c|c|c|}
\hline \multicolumn{4}{|c|}{ A Resposta de Prometeu } \\
\hline $\begin{array}{l}\text { Ecossistemas e natureza } \\
\text { não existem, recursos } \\
\text { naturais são criados ao } \\
\text { serem transformados } \\
\text { pelos seres humanos. } \\
\text { Com o crescimento } \\
\text { econômico é possível } \\
\text { acabar com a poluição, } \\
\text { fazer saneamento } \\
\text { adequado, ter água } \\
\text { potável }\end{array}$ & $\begin{array}{l}\text { Os humanos dominam } \\
\text { tudo. } \\
\text { Ênfase na competição } \\
\text { como forma de inovação } \\
\text { e superação da escassez. } \\
\text { Crença no mercado como } \\
\text { melhor modo de } \\
\text { organizar a economia e a } \\
\text { sociedade sem } \\
\text { intervenção do estatal }\end{array}$ & $\begin{array}{c}\text { Capacidade de ação é } \\
\text { para todos como atores } \\
\text { econômicos }\end{array}$ & $\begin{array}{l}\text { Máquinas e mecânica } \\
\text { construídas de } \\
\text { componentes simples. } \\
\text { A retórica vem das } \\
\text { tendências: queda nos } \\
\text { preços dos insumos, } \\
\text { aumento na expectativa de } \\
\text { vida }\end{array}$ \\
\hline
\end{tabular}

Fonte: Dryzek, 1997, p. 37 e 53.

\section{Resolução de problemas}

O discurso de resolução de problemas engloba três subtipos: o discurso da racionalidade administrativa, o discurso do pragmatismo democrático e o discurso do racionalismo econômico. A racionalidade administrativa busca organizar conhecimentos científicos e técnicos em favor da burocracia do governo. O governo é tratado sob uma perspectiva técnica, racional, voltado para a resolução de problemas. Sua percepção sobre o meio ambiente é tratada como agnóstica, de forma que nem os posicionamentos dos sobrevivencialistas nem os dos defensores do discurso de Prometeu são defendidos ou refutados. Assim, esse discurso se estrutura sobre a lógica de que a natureza se submete à capacidade de resolução humana de problemas, sendo que o povo se submete ao Estado, e este é controlado por especialistas e gestores. A atuação dos especialistas e gestores é motivada pelo interesse público, mas é conceitualizada em termos unitários. Em termos de metáforas, a principal é da mente administrativa unitária e onisciente, que representa o Estado.

O pragmatismo democrático é uma resposta à racionalidade administrativa e busca reajustar sua forma de resolver os problemas ambientais. Ao invés de deixar todas as ações a cargo das instâncias governamentais, esse discurso defende a participação das pessoas no debate ambiental. O Estado é uma entidade mais porosa, aberta à participação dos cidadãos. Nessa concepção, as relações são marcadas pela isonomia entre os cidadãos - todos podem participar das questões ambientais -, mas as interações entre os atores misturam elementos de cooperação e de competição. Como são muitos atores envolvidos, os seus interesses também são difusos e variados, contemplando o interesse público e também interesses materiais próprios. As metáforas utilizadas nesse discurso remetem ao entendimento das políticas públicas como resultado de várias forças e à comparação da vontade e da participação social com um termostato, que ajuda a manter o equilíbrio do sistema.

Finalizando o discurso de resolução de problemas, apresenta-se o racionalismo econômico, discurso que se manifestou de forma expressiva durante as décadas de 80 e 90 e que aposta na ação inteligente dos mecanismos de mercado para alcançar o interesse público. O principal argumento do racionalismo econômico é derivado da metáfora de "A Tragédia dos Comuns" (HARDIN, 1968): as pessoas dão mais importância aos interesses privados do que aos interesses públicos. Assim, a proposta seria a de privatizar os recursos naturais e inseri-los no sistema de mercado, bem como a de estabelecer mecanismos de mercado que incentivem ou restrinjam a utilização de determinados recursos. 
A ontologia do discurso do racionalismo econômico considera os atores - individuais ou coletivos - como econômicos e motivados por interesses materiais, mas também admite a necessidade de alguma entidade responsável por cuidar do interesse público. Assim, o governo é um ator que possui seu papel dentro desse discurso, porque, ademais de ser responsável pelo interesse público, interfere e participa das atividades de mercado por meio da tributação e do controle da moeda, sendo impossível a existência de estruturas governadas apenas pelos mercados (MEIRELLES, 2010). Os defensores desse discurso reconhecem que os recursos naturais são finitos e, por isso, as relações entre os atores são competitivas. A relação da natureza com o homem resume-se ao fato de que os recursos naturais são inputs para o sistema social e econômico que atende às necessidades humanas, a qual estabelece a metáfora mecanicista utilizada neste discurso. Outros mecanismos retóricos dão ênfase à palavra "liberdade", como os termos "free-market", "freeenterprise". Por outro lado, a gestão governamental dos recursos naturais é estigmatizada, pregando-se soluções de mercado. Conforme aponta Dryzek (1997), o racionalismo econômico foi um dos discursos predominantes no Relatório Brundtland, "Nosso Futuro Comum" (UNITED NATIONS, 1987), com a promoção de instrumentos de mercado como solução política. Outro discurso que teve relevância no mesmo documento foi o da sustentabilidade apresentado a seguir.

Quadro 4

Analisando o Discurso: Resolução de Problemas

\begin{tabular}{|c|c|c|c|}
\hline Ontologia & $\begin{array}{c}\text { Hipóteses sobre relações } \\
\text { naturais }\end{array}$ & Agentes e Motivações & Metáforas \\
\hline \multicolumn{4}{|c|}{ Racionalidade Administrativa } \\
\hline $\begin{array}{l}\text { Capitalismo liberal } \\
\text { Estado gerencial } \\
\text { Especialistas } \\
\text { Gestores }\end{array}$ & $\begin{array}{l}\text { A natureza se submete à } \\
\text { capacidade de resolução } \\
\text { humana de problemas; } \\
\text { O povo se submete ao } \\
\text { Estado; } \\
\text { Especialistas e gestores } \\
\text { controlam o Estado }\end{array}$ & $\begin{array}{c}\text { Especialistas e Gestores } \\
\text { Motivados pelo } \\
\text { interesse público, } \\
\text { definido em moldes } \\
\text { unitários }\end{array}$ & $\begin{array}{l}\text { Mistura de preocupação e } \\
\text { reconforto; } \\
\text { A "mente gerencial" }\end{array}$ \\
\hline \multicolumn{4}{|c|}{ Pragmatismo Democrático } \\
\hline $\begin{array}{l}\text { Capitalismo Liberal } \\
\text { Democracia Liberal } \\
\text { Cidadãos }\end{array}$ & $\begin{array}{l}\text { Igualdade entre os } \\
\text { cidadãos } \\
\text { Relacionamentos políticos } \\
\text { interativos, misto de } \\
\text { competição e cooperação }\end{array}$ & $\begin{array}{c}\text { Muitos agentes } \\
\text { diferentes } \\
\text { Motivações são mix de } \\
\text { autointeresse e } \\
\text { múltiplas concepções } \\
\text { de interesse público }\end{array}$ & $\begin{array}{l}\text { Políticas públicas resultam } \\
\text { de forças } \\
\text { Políticas são experimentos } \\
\text { científicos } \\
\text { Termostato }\end{array}$ \\
\hline \multicolumn{4}{|c|}{ Racionalismo Econômico } \\
\hline $\begin{array}{l}\text { Homo econômico } \\
\text { Mercado } \\
\text { Preços } \\
\text { Propriedade } \\
\text { Governos }\end{array}$ & $\begin{array}{c}\text { Competição } \\
\text { Hierarquia baseada na } \\
\text { expertise } \\
\text { Subordinação à natureza }\end{array}$ & $\begin{array}{l}\text { Homo-econômico: } \\
\text { autointeressado } \\
\text { Alguns servidores } \\
\text { podem ser motivados } \\
\text { pelo interesse público }\end{array}$ & $\begin{array}{c}\text { Mecanicista } \\
\text { Estigmatiza a regulação } \\
\text { administrativa } \\
\text { Conexão com liberdade } \\
\text { Histórias de terror }\end{array}$ \\
\hline
\end{tabular}

Fonte: Dryzek, 1997, p. 76, 97 e 115. 


\section{Sustentabilidade}

O discurso da sustentabilidade subdivide-se em duas vertentes: a do desenvolvimento sustentável e a da modernização ecológica. O desenvolvimento sustentável é um dos discursos ambientais mais influentes, mas, talvez, um dos mais ambíguos. Dryzek (1997) comenta que existem dúvidas sobre o que, de fato, significa o termo "desenvolvimento sustentável", sendo que inúmeras definições já foram formuladas, inclusive como forma de colocar as ideias e os interesses de outros discursos (como o do sobrevivencialismo) em nova roupagem. A essência do discurso baseia-se na compreensão de que o desenvolvimento econômico é necessário, principalmente para atender às necessidades dos países mais pobres, mas que estes não poderão seguir o caminho trilhado pelos países ricos, pois o planeta Terra não suportaria. Assim, é necessário que o desenvolvimento econômico seja guiado por princípios ambientais e sociais.

O discurso do desenvolvimento sustentável defende que o ambiente não é um sistema em separado dos sistemas sociais e econômicos, e que o crescimento econômico, a justiça social e a sustentabilidade de longo prazo são objetivos que se fortalecem mutuamente, numa relação de cooperação. Os principais atores são as organizações transnacionais e as organizações não governamentais, além dos atores locais. As metáforas utilizadas são as que abordam o desenvolvimento das sociedades como algo orgânico, que necessita crescer e se desenvolver; ou de um ser humano que, com o passar do tempo, vai tornando-se mais sensível, cuidadoso e inteligente. Reafirma a tese de que é possível ter tudo: crescimento econômico, justiça social e conservação do meio ambiente.

O discurso da modernização ecológica assemelha-se ao discurso do desenvolvimento sustentável por ser baseado em valores e princípios que defendem que todos ganham com a preservação do meio ambiente, mas enfatiza os ganhos dos quais os empresários e industriais do sistema capitalista também podem desfrutar. A modernização ecológica percebe o meio ambiente como uma fonte de recursos e como um reciclador de poluentes, não como o lugar onde vivemos como o discurso do desenvolvimento sustentável. Os principais atores são os governos, as empresas, os ambientalistas reformistas e os cientistas, sendo que as relações entre eles devem se basear na cooperação, tendo o consenso como elemento-chave de suas deliberações. As metáforas neste discurso são a casa arrumada, onde a Terra se mantém limpa e organizada pela minimização do desperdício. A palavra modernização é associada à ideia de progresso, no sentido defendido tanto pelos industrialistas, quanto por marxistas, social-democratas e liberais, de que a história se move em direção ao avanço do desenvolvimento social. Entretanto, esse discurso não se preocupa muito com a justiça social, ao contrário do desenvolvimento sustentável, nem com a trajetória dos países pobres.

Entretanto, a sustentabilidade não é "privativa" do discurso do desenvolvimento sustentável e da modernização ecológica. Pelo fato de ter sido o discurso dominante há mais de trinta anos, expoentes de outros discursos utilizam a sustentabilidade para propagar suas ideias na direção mais conveniente. Trata-se de um veículo para os ambientalistas perseguirem seus objetivos (LAFFERTY, 1996, apud DRYZEK, 1997, p. 135) 
Quadro 5

Analisando o Discurso: Sustentabilidade

\begin{tabular}{|c|c|c|c|}
\hline Ontologia & $\begin{array}{l}\text { Hipóteses sobre } \\
\text { relações naturais }\end{array}$ & Agentes e Motivações & Metáforas \\
\hline \multicolumn{4}{|c|}{ Desenvolvimento Sustentável } \\
\hline $\begin{array}{l}\text { Sistemas ecológicos e } \\
\text { sociais estruturados do } \\
\text { global para o local } \\
\text { Economia Capitalista } \\
\text { Não há limites }\end{array}$ & $\begin{array}{c}\text { Subordinação da } \\
\text { natureza aos seres } \\
\text { humanos } \\
\text { Crescimento } \\
\text { econômico, proteção } \\
\text { ambiental, justiça } \\
\text { distributiva e } \\
\text { sustentabilidade de } \\
\text { longo prazo ao mesmo } \\
\text { tempo }\end{array}$ & $\begin{array}{l}\text { Muitos agentes nos } \\
\text { diferentes níveis, } \\
\text { notadamente no } \\
\text { internacional e local ao } \\
\text { invés do estatal, } \\
\text { motivados pelo bem } \\
\text { público. }\end{array}$ & $\begin{array}{c}\text { Crescimento orgânico } \\
\text { Conexão para o progresso } \\
\text { É possível ter tudo: } \\
\text { crescimento econômico, } \\
\text { conservação ambiental e } \\
\text { justiça social }\end{array}$ \\
\hline \multicolumn{4}{|c|}{ Modernização Ecológica } \\
\hline $\begin{array}{c}\text { Sistemas complexos } \\
\text { Economia Capitalista } \\
\text { O Estado } \\
\text { Natureza como estação } \\
\text { de tratamento de } \\
\text { resíduos }\end{array}$ & $\begin{array}{l}\text { Subordinação da } \\
\text { natureza } \\
\text { Proteção ambiental e } \\
\text { Prosperidade } \\
\text { econômica andam } \\
\text { juntas }\end{array}$ & $\begin{array}{l}\text { Parcerias motivadas pelo } \\
\text { bem público } \\
\text { Parceria entre governo, } \\
\text { empresas, } \\
\text { ambientalistas, cientistas }\end{array}$ & $\begin{array}{c}\text { Casa arrumada } \\
\text { Progresso } \\
\text { É possível ter tudo }\end{array}$ \\
\hline
\end{tabular}

Fonte: Dryzek, 1997, p.132 e 146.

\section{Radicalismo verde}

O discurso do radicalismo verde critica o status quo englobando uma imensa variedade de ideologias, movimentos, grupos e pensadores. Possui duas subcategorias: a dos românticos e a dos racionalistas. A categoria dos românticos acredita que as relações do ser humano com o meio ambiente devem ser mudadas por meio de novas experiências e da sensibilização do homem. Os românticos não estão preocupados com melhores políticas ou instituições que possam direcionar o comportamento humano rumo à preservação do ambiente, mas com a subjetividade. Subdividem-se em ecologia profunda, ecofeminismo cultural, biorregionalismo, estilo de vida verde, ecoteologia e ecocomunitarismo, de acordo com o quadro abaixo: 
Quadro 6

Variedades de Romantismo Verde e Suas Características Centrais

\begin{tabular}{|c|c|}
\hline Variedades & Característica Central \\
\hline $\begin{array}{l}\text { Ecologia Profunda (Deep } \\
\text { Ecology) }\end{array}$ & $\begin{array}{c}\text { Consciência da unidade orgânica self-in-Self } \\
\text { Igualdade biocêntrica sem arrogância humana (misantropia) } \\
\text { Necessidades vitais } \\
\text { Preservação e proteção da vida selvagem }\end{array}$ \\
\hline Ecofeminismo Cultural & $\begin{array}{c}\text { Luta contra antropocentrismo e machismo } \\
\text { Libertação feminina leva à libertação da Natureza } \\
\text { Divindade, santidade do feminino }\end{array}$ \\
\hline $\begin{array}{l}\text { Biorregionalismo } \\
\text { (espacial) }\end{array}$ & Indivíduo como parte de seu ecossistema \\
\hline Estilo de Vida Verde & $\begin{array}{l}\text { Adoção de outro estilo de vida, experiência pós-industrial } \\
\qquad \text { Rejeição de rótulo político }\end{array}$ \\
\hline Ecoteologia & $\begin{array}{l}\text { Afastamento (judaico-cristão) de Deus da natureza } \\
\qquad \begin{array}{l}\text { Base espiritual, orientação religiosa } \\
\text { Atitude contemplativa e reverencial }\end{array}\end{array}$ \\
\hline Ecocomunitarismo & $\begin{array}{l}\text { Afastamento monástico da sociedade humana } \\
\text { Novo espírito, nova cultura }\end{array}$ \\
\hline
\end{tabular}

Fonte: Dryzek, 1997, p. 156-162.

Os racionalistas, por sua vez, acreditam que mudanças devem ocorrer por meio de uma ação política radical e mudanças estruturais. A mudança individual e de subjetividades são bem-vindas, mas não são capazes de atingir as causas dos problemas, que são as relações sociais complexas. Os homens são especiais, pois possuem capacidade de raciocínio, mas isso não permite que tenham licença para dominar a natureza. Acreditam na igualdade entre os indivíduos para o engajamento no debate sobre questões coletivas. A ação política pode ser individual ou coletiva, por meio de movimentos sociais, partidos, estados. As metáforas são orgânicas e ligadas à potencial racionalidade das estruturas sociais. Para os racionalistas, as políticas públicas e as instituições são essenciais para lidar com os múltiplos interesses sociais e econômicos relacionados ao meio ambiente. Nesse sentido, o racionalismo verde é mais abrangente que o romantismo. Trata-se de um discurso que também possui várias vertentes: os verdes europeus, a ecologia social, a justiça ambiental, o ecofeminismo social, o biorregionalismo, a esquerda verde e a liberação dos animais. Suas características são explicitadas no Quadro 7. 
Quadro 7

Variedades de Racionalismo Verde e Suas Características Centrais

\begin{tabular}{|c|c|}
\hline Variedades & Característica Central \\
\hline Os "Verdes" Europeus & $\begin{array}{l}\text { Partidos políticos europeus } \\
\text { Faç̧ões distintas (aceitação do jogo político) }\end{array}$ \\
\hline Ecologia Social & $\begin{array}{l}\text { Rival da ecologia profunda (deep ecology) } \\
\text { Ênfase na dimensão social e cultural do tema } \\
\text { Hierarquia não natural }\end{array}$ \\
\hline Justiça Ambiental & $\begin{array}{c}\text { Ação pragmática em causas particulares } \\
\text { NIMBY (Not in my Backyard) } \rightarrow \text { NIABY (Not in Anybody's Backyard) } \\
\text { Redes }\end{array}$ \\
\hline Ecofeminismo Social & $\begin{array}{l}\text { Machismo como elemento central } \\
\text { Outros elementos opressores }\end{array}$ \\
\hline Biorregionalismo (político) & $\begin{array}{l}\text { Estruturas político-econômicas redesenhadas regionalmente } \\
\text { Aproxima-se do racionalismo administrativo }\end{array}$ \\
\hline $\begin{array}{l}\text { Esquerda Verde } \\
\text { (eco-marxismo) }\end{array}$ & $\begin{array}{l}\text { Questão ambiental como contradição do capitalismo } \\
\text { Eco-marxismo }\end{array}$ \\
\hline Liberação dos Animais & $\begin{array}{l}\text { Direitos dos animais, nova onda iluminista } \\
\text { Peter Singer (base em J. Bentham) } \\
\text { Pouco ecológico (holístico) }\end{array}$ \\
\hline
\end{tabular}

Fonte: Dryzek, 1997, p. 173-184.

Ambas as categorias acreditam que os recursos naturais são finitos, mas os românticos defendem que a mudança deve vir de dentro, não ser imposta por outros, enquanto os racionalistas demandam urgência para evitar crises futuras. As relações devem ser naturais, igualitárias entre os seres humanos, e, para os românticos, também entre os seres humanos e o ambiente que os cerca. As metáforas utilizadas pelos românticos enfocam sentimentos, emoções, intuição; as utilizadas pelos racionalistas visam à razão e ao progresso. 
Quadro 8

\section{Analisando o Discurso: Radicalismo Verde}

\begin{tabular}{|c|c|c|c|}
\hline Ontologia & $\begin{array}{c}\text { Hipóteses sobre relações } \\
\text { naturais }\end{array}$ & $\begin{array}{l}\text { Agentes e } \\
\text { Motivações }\end{array}$ & Metáforas \\
\hline \multicolumn{4}{|c|}{ Romantismo Verde } \\
\hline $\begin{array}{c}\text { Limites Globais } \\
\text { Natureza Interna } \\
\text { Natureza externa } \\
\text { Subjetividade e } \\
\text { Consciência individual }\end{array}$ & $\begin{array}{c}\text { Relações entre seres } \\
\text { humanos e natureza são } \\
\text { naturais, mas foram } \\
\text { violadas } \\
\text { Igualdade entre } \\
\text { humanidade e natureza }\end{array}$ & $\begin{array}{l}\text { Indivíduos, alguns } \\
\text { mais conscientes que } \\
\text { outros } \\
\text { A natureza (Gaia) } \\
\text { Grupos } \\
\text { historicamente } \\
\text { ignorados }\end{array}$ & $\begin{array}{c}\text { Biológicas e orgânicas } \\
\text { Apelo emocional e a } \\
\text { intuição } \\
\text { Paixão }\end{array}$ \\
\hline \multicolumn{4}{|c|}{ Racionalismo Verde } \\
\hline $\begin{array}{l}\text { Limites globais } \\
\text { Seres humanos racionais } \\
\text { Natureza como } \\
\text { ecossistemas complexos } \\
\text { Estruturas políticas } \\
\text { sociais e econômicas são } \\
\text { importantes }\end{array}$ & $\begin{array}{l}\text { Igualdade entre pessoas } \\
\text { Relações complexas } \\
\text { entre o ser humano e a } \\
\text { natureza }\end{array}$ & $\begin{array}{l}\text { Indivíduos e } \\
\text { coletividades } \\
\text { Motivações } \\
\text { multidimensionais }\end{array}$ & $\begin{array}{c}\text { Orgânicas } \\
\text { Apelo à razão } \\
\text { Progresso }\end{array}$ \\
\hline
\end{tabular}

Fonte: Dryzek, 1997, p.167 e 188.

\section{O futuro que Queremos: Analisando o Discurso da Rio +20}

\section{Da Rio 92 para a Rio + 20}

Em 1992, ocorreu a Conferência das Nações Unidas sobre Meio Ambiente e Desenvolvimento, que consolidou o conceito de desenvolvimento sustentável, marcando a convergência entre propostas de desenvolvimento e de proteção ambiental. Dez anos após, foi realizada a Cúpula Mundial sobre Desenvolvimento Sustentável (Rio +10) com o objetivo de analisar os resultados alcançados e indicar o caminho a ser seguido para implementação dos compromissos. Entretanto, muito pouco foi efetivamente realizado após a Rio +10 . As inúmeras conferências sobre mudanças climáticas (COPs) e outros encontros realizados para discutir problemas como o aquecimento global, aumento da desertificação, perda da biodiversidade, impactos ambientais em populações vulneráveis, apresentaram poucos avanços.

A Conferência das Nações Unidas sobre Desenvolvimento Sustentável (Rio+20) foi realizada com o propósito de superar o impasse dos anos anteriores e definir a agenda ambiental para as próximas décadas. Mais especificamente, o objetivo da conferência foi o de renovar o compromisso político com o desenvolvimento sustentável, avaliando o progresso e as lacunas na implementação da agenda ambiental, bem como discutindo e tratando temas novos e emergentes. Da Rio+20 resultou o relatório "The Future We Want", (UNITED NATIONS, 2012) que será a base para a análise do discurso ambiental atual e seus possíveis impactos. 


\section{Ontologia da Rio +20: Entes Fundamentais Reconhecidos}

O documento não contesta a estrutura da economia capitalista, porém declara na abertura que erradicar a pobreza é o maior desafio para o mundo e pré-condição para o desenvolvimento sustentável (UNITED NATIONS, 2012, parag. 2). O documento defende a visão de que a humanidade tem habilidade para atender às necessidades das gerações presentes sem comprometer a habilidade de as gerações futuras suprirem suas próprias necessidades. Esse conceito, lançado pelo Relatório Brundtland (1987), é o coração da ideia do desenvolvimento sustentável e também serviu de base filosófica da Rio 92. Esta habilidade é possível por meio da interação entre três pilares: crescimento inclusivo, desenvolvimento social e proteção ambiental.

O documento foi organizado em volta de dois pontos principais: a economia verde e a criação do arcabouço institucional para o desenvolvimento sustentável. Grande importância é atribuída à criação de instituições e estruturas para integrar as perspectivas, promover participação e coerência, e implementar políticas científicas para o desenvolvimento sustentável nos países (UNITED NATIONS, 2012, parag. 75-103).

\section{Hipóteses sobre relações naturais}

No que tocam às hipóteses sobre as relações naturais é clara a posição de que as pessoas são o centro da sustentabilidade, e de que há subordinação da natureza aos seres humanos. Há um apelo na abertura por relações justas, equitativas e inclusivas (UNITED NATIONS, 2012, parag. 5-6). Foi dada ênfase à parceria entre grupos e atores em prol do bem comum. Porém, foi confirmado o princípio de que países ricos e pobres possuem responsabilidades comuns, mas diferenciadas. Este ponto foi bastante suavizado e simplificado no documento final, mas fica clara a maior preocupação com a redução das diferenças entre países desenvolvidos e em desenvolvimento (UNITED NATIONS, 2012, parag. 19-41).

É feita uma abordagem holística e integrada do desenvolvimento sustentável, onde o crescimento econômico, a proteção ambiental e a justiça distributiva podem ocorrer simultaneamente (UNITED NATIONS, 2012, parag. 6). Entretanto, no decorrer do documento, os aspectos econômicos ganharam uma força comparativamente superior aos aspectos ambientais em senso estrito e aos aspectos sociais, como se o ambiental se subordinasse ao econômico (ibdem, parag. 56-74).

\section{Agentes e Motivações}

É reconhecida a diversificação dos atores envolvidos no tema, convocando a participação efetiva de todos os países, principalmente dos países em desenvolvimento (UNITED NATIONS, 2012, parag. 20). O documento afirma o papel e convida o engajamento ativo na promoção, planejamento e implementação do desenvolvimento sustentável de todos os níveis de governo, legislativos, judiciários, níveis locais e subnacionais e de grupos como: mulheres, crianças, jovens, ONGs, indígenas, trabalhadores, sindicatos, empresas, indústrias, fazendeiros, comunidade científica e tecnológica, sociedade civil, comunidades e autoridades locais, voluntários, migrantes, idosos e pessoas deficientes (ibdem, parag. 43). Assim, os grupos e as instâncias governamentais ganham destaque como atores que possuem a ação política na área ambiental.

O documento enfatiza a liderança das mulheres, decidindo promover a igualdade de gênero e o empoderamento para assegurar a participação feminina efetiva no processo. Nesse sentido, demanda a extinção de leis discriminatórias, o acesso igual à justiça, educação, saúde, terra, crédito e às decisões políticas e econômicas. O documento solicita a coleta, análise e uso de indicadores sensíveis a gênero na formulação de programas. Da mesma forma, reitera o papel das mulheres camponesas como agentes do desenvolvimento rural, agrícola e da segurança alimentar (UNITED NATIONS, 2012, parag. 45, 109, 236-244). Apesar do destaque às mulheres, a expressão "direitos reprodutivos", que designa a autonomia 
da mulher para decidir quando ter filhos, foi retirada do texto final por pressão do Vaticano. Essa decisão demonstra o tipo de conflito envolvido na formulação de uma instituição como essa.

\section{Metáforas e outros mecanismos retóricos}

Em sua abertura, o documento "The Future We Want" utiliza como recurso retórico o resgate e reafirmação das cúpulas ambientais anteriores, como forma de facilitar o convencimento e a aceitação do que vem depois ${ }^{4}$ reconhecendo o caminho já percorrido (UNITED NATIONS, 2012, parag. 16-17). O documento reconhece o "progresso desigual" em relação ao desenvolvimento sustentável e à erradicação da pobreza. Essa é uma das menções mais claras à tensão e oposição entre países ricos e pobres, que permeou todo o processo da Rio +20 . Tal tensão vem de Estocolmo, foi amenizada na Rio 92 e ganhou força novamente. $\mathrm{O}$ documento atribui a falta de progresso às múltiplas crises dos últimos anos, como a financeira, econômica, dos alimentos, energética, atribuindo a maior parte dos seus impactos aos países em desenvolvimento. Entretanto, o documento não atribui culpa aos países desenvolvidos pela crise financeira.

O documento também utiliza metáforas comuns a outros discursos como a Terra é a nossa casa, nossa mãe. Os direitos da Declaração Universal dos Direitos Humanos, de aceitação ampla, são usados para defender princípios como paz, liberdade, educação, saúde, justiça, segurança, bem como para defender princípios liberais, como democracia e Estado de direito.

A metáfora da "economia verde" foi bastante forte, apresentada como uma novidade do discurso atual em oposição a uma "economia marrom" ou "suja". Esta metáfora resume o sistema de atividades econômicas relacionadas à produção, distribuição e consumo de bens e serviços que aumentarão o bem estar humano no longo prazo, sem expor as futuras gerações a riscos ambientais e à escassez ecológica.

O documento destaca que não devem ser impostas regras rígidas à economia verde, e que a soberania nacional de cada país deve ser respeitada. Antecipa que o conceito pode ser usado como barreira não tarifária e alerta que não deve ser usada como "uma restrição disfarçada ao comércio internacional". O documento defende que a economia verde deve contribuir para diminuir as diferenças tecnológicas entre países desenvolvidos e em desenvolvimento. As ONGs presentes na Cúpula dos Povos atacaram a metáfora, afirmando que o termo é usado para mascarar os malefícios do sistema de mercado, o consumo desenfreado e a necessidade inesgotável de crescimento.

${ }^{4}$ As cúpulas citadas são: Rio Declaration on Environment and Development, Agenda 21, Johannesburg Declaration on Sustainable Development, World Summit on Sustainable Development, Barbados Program of Action and the Mauritius Strategy for Implementation, Istanbul Program of Action for Least Developed Countries (IPOA), Almaty Program of Action for Landlocked Developing Countries, Political Declaration on Africa's Development Needs, New Partnership for Africa's Development, UN Millennium Declaration and 2005 World Summit, Monterrey Consensus and Doha Declaration on Financing for Development, UN General Assembly on the MDGs, International Conference on Population and Development, Beijing Declaration and Platform for Action, United Nations Framework Convention on Climate Change (UNFCCC), Convention on Biological Diversity (CBD) and the United Nations Convention to Combat Desertification (UNCCD). 
Quadro 9

\section{Análise do discurso da Rio +20}

\begin{tabular}{|c|c|c|c|}
\hline Ontologia & $\begin{array}{l}\text { Hipóteses sobre } \\
\text { relações naturais }\end{array}$ & Agentes e Motivações & Metáforas \\
\hline $\begin{array}{l}\text { Economia Capitalista } \\
\text { Erradicar a pobreza é o } \\
\text { maior desafio para o } \\
\text { mundo e condição do } \\
\text { desenvolvimento } \\
\text { sustentável } \\
\text { Desenvolvimento } \\
\text { sustentável tem três } \\
\text { dimensões: } \\
\text { crescimento inclusivo, } \\
\text { avanço social e } \\
\text { proteção ambiental } \\
\text { As pessoas são o centro } \\
\text { da sustentabilidade }\end{array}$ & $\begin{array}{c}\text { Relações cooperativas } \\
\text { entre os atores } \\
\text { Abordagem holística e } \\
\text { integrada do } \\
\text { desenvolvimento } \\
\text { sustentável } \\
\text { Subordinação de facto } \\
\text { do ambiental ao } \\
\text { econômico } \\
\text { Aliança entre as } \\
\text { pessoas, governos, } \\
\text { sociedade civil e setor } \\
\text { privado } \\
\text { Responsabilidades } \\
\text { comuns e diferenciadas } \\
\text { Ricos x Pobres }\end{array}$ & $\begin{array}{l}\text { População é formada por grupos } \\
\text { e instâncias governamentais } \\
\text { Afirma papel e convoca o } \\
\text { engajamento ativo na promoção, } \\
\text { planejamento e implementação } \\
\text { do desenvolvimento sustentável } \\
\text { de todos os níveis de governo, } \\
\text { legislativos, judiciários, níveis } \\
\text { locais e subnacionais e dos } \\
\text { grupos: mulheres, crianças, } \\
\text { jovens, ONGs, indígenas, } \\
\text { trabalhadores, sindicatos, } \\
\text { empresas, indústrias, fazendeiros, } \\
\text { comunidade científica e } \\
\text { tecnológica, migrantes, idosos. }\end{array}$ & $\begin{array}{l}\text { Casa, Mãe terra } \\
\text { Libertar a } \\
\text { Humanidade da } \\
\text { Pobreza e Fome } \\
\text { Gerações Futuras } \\
\text { Economia Verde } \\
\text { Saúde e Integridade } \\
\text { dos Ecossistemas } \\
\text { Liberdade, Paz e } \\
\text { Segurança } \\
\text { Direito à } \\
\text { alimentação, } \\
\text { igualdade de } \\
\text { gênero, Estado de } \\
\text { direito, justiça, } \\
\text { equidade, }\end{array}$ \\
\hline
\end{tabular}

Fonte: Elaboração dos Autores.

\section{Comparando o Discurso da Rio +20 e os Discursos Ambientais Prévios}

A análise comparada do discurso do documento "The Future We Want" com os discursos ambientais prévios demonstra que ele é baseado no discurso do desenvolvimento sustentável. Porém, as indicações de ação futura apontam em direção ao discurso do racionalismo econômico.

A ontologia do documento utiliza o desenvolvimento sustentável como princípio, dado seu conceito amplo e abstrato. Por sua vez, o racionalismo econômico traz meios mais concretos para implementar os princípios da sustentabilidade. Segundo Bertha Becker (2012, p. 10), essa visão de mundo serve aos interesses geopolíticos dos países desenvolvidos, significando a abertura de novos mercados. Há interesse em ampliar o controle sobre as grandes reservas de recursos naturais dos países em desenvolvimento, pois a tecnologia para a expansão pertence aos países ricos.

No que tocam às hipóteses sobre as relações naturais, é clara a subordinação da natureza aos seres humanos, ou seja, a visão antropocêntrica da relação homem-natureza. A Rio +20 continuou a ênfase na parceria entre grupos e atores em prol do bem comum, reconhecendo, porém, que países ricos e pobres possuem responsabilidades comuns, mas diferenciadas. Este ponto foi bastante suavizado no documento final, mas fica clara a maior preocupação com a redução das diferenças entre países desenvolvidos e em desenvolvimento. 
No que se refere aos agentes e suas motivações, o documento dá continuidade ao discurso da sustentabilidade, no qual a população é formada por grupos que podem agir em parceria. A Rio+20 procura abranger o maior número possível de grupos, do nível global ao local. Porém, o documento deixa de lado o fato de que estes grupos podem ter interesses bastante díspares e multidimensionais. Em outras palavras, esvaziou-se a criticidade em relação ao status quo.

As metáforas da Rio +20 derivam de vários discursos. Do sobrevivencialismo vieram as imagens de "Casa e Mãe terra". Foram também utilizados apelos emocionais e orgânicos típicos do radicalismo verde como "libertar a humanidade da pobreza e da fome" e "saúde e integridade dos ecossistemas", "harmonia com a natureza". As mais relevantes vieram do desenvolvimento sustentável como a reafirmação incansável de que "é possível ter tudo: crescimento econômico, conservação ambiental e justiça social" e a preocupação com a preservação para as "gerações futuras". A grande novidade foi a metáfora da "economia verde", que, justamente por ser nova, foi a que gerou mais polêmica, tanto na imprensa quanto na Cúpula dos Povos.

A Rio +20 trouxe como elemento importante a ênfase na erradicação da pobreza e da fome como questão central para o ambientalismo e condição para o desenvolvimento sustentável. Esse fato reflete a maior influência dos países emergentes nos fóruns internacionais e o papel do Brasil como coordenador do documento. A metáfora de economia verde, um novo elemento do discurso, foi objeto de controvérsia, tanto na fase das negociações quanto durante a Rio +20 . Para as Nações Unidas, o conceito de economia verde é utilizado para ilustrar a viabilidade de haver crescimento econômico e proteção ambiental simultaneamente.

Becker adverte ainda que por trás da metáfora há uma tentativa de superar a crise econômica, pela expansão do sistema por múltiplos meios, inclusive sobre os recursos naturais. Assim como o desenvolvimento sustentável, a economia verde é uma ideia vaga, o que facilitaria a adesão (2012, p.14), já que ninguém é contra a reciclagem, a energia limpa ou a redução das emissões.

Para Flávio Comin (2012), o debate em torno da economia verde reduziu o universo de objetivos a serem alcançados, pois "o respeito à natureza não deve ser fruto do cálculo econômico, mas da convicção dos indivíduos sobre o valor intrínseco do meio ambiente".

\section{Discursos Paralelos à Rio+20}

A Rio + 20 contou com vários eventos paralelos, como a Cúpula dos Povos, a Cúpula dos Prefeitos, a Cúpula das Mulheres Chefes de Estado, a Cúpula da Cidadania Inclusiva e do Voluntariado, a Cúpula Mundial de Estados e Regiões, a Cúpula dos Legisladores. Organizados por movimentos civis, empresas, ambientalistas, além de outros grupos de diferentes esferas e setores governamentais. Esses eventos tiveram o objetivo de discutir questões ambientais e de articular propostas e agendas comuns.

\section{Cúpula dos Povos}

A Cúpula dos Povos foi uma das que teve maior repercussão na mídia. Participaram das discussões movimentos sociais e populares, sindicatos, povos, organizações da sociedade civil e ambientalistas de todo o mundo, e os resultados foram compilados na "Declaração Final da Cúpula dos Povos por Justiça Social e Ambiental". O discurso dominante desse documento é que precisa haver convergência entre os movimentos de mulheres, indígenas, negros, juventudes, agricultores/as, familiares e camponeses, trabalhadores/as, povos e comunidades tradicionais, quilombolas, lutadores pelo direito à cidade, e religiões de todo o mundo para que se possam combater os interesses das grandes corporações e do capital financeiro que dominam hoje a agenda dos governos e são os grandes responsáveis pela crise estrutural pela qual o mundo está passando. Trata-se de um discurso, portanto, antagônico ao do racionalismo econômico e administrativo: nem o Estado, 
nem o mercado são agentes confiáveis na tarefa de preservar o meio ambiente. Assim, trata-se do discurso do radicalismo verde, com algumas variações.

Segundo a Declaração Final da Cúpula dos Povos, houve uma captura corporativa da ONU e dos governos em prol dos interesses das corporações. Existe a ideia de que a humanidade e o meio ambiente correm riscos de destruição, e que a Rio+ 20 não se posiciona de forma a mudar esse quadro, mas apenas "repete o falido roteiro de falsas soluções defendidas pelos mesmos atores que provocaram a crise global" (CÚPULA DOS POVOS, 2012).

De acordo com o documento, os recursos ambientais precisam parar de ser tratados como inputs do processo produtivo capitalista e devem ser reconhecidos como direitos da humanidade. Assim, o discurso da Cúpula dos Povos sugere uma mudança ontológica, que saia da perspectiva realista - os recursos naturais como inputs do processo produtivo capitalista - para uma perspectiva nominalista - os recursos naturais como direitos da humanidade, a serem protegidos e preservados por todos.

Ademais, os países altamente industrializados têm uma dívida ambiental histórica com o resto do mundo e precisam se comprometer com ela. No entanto, ao contrário, os países ricos se esquivam de suas obrigações e continuam a exercer seus interesses. Usam, para tanto, uma nova roupagem: a economia verde, a qual seria apenas uma forma de continuar a exercer atividades de cunho capitalista, mas sob o aval do "corretamente político".

As soluções propostas para tornar o meio ambiente um direito de todos incluem a defesa dos espaços públicos nas cidades, com gestão democrática e participação popular; a economia cooperativa e solidária; o estabelecimento de um novo paradigma de produção, distribuição e consumo; a mudança da matriz energética, com a adoção de um modelo baseado em energias renováveis descentralizadas e que garantam energia para a população; a instituição de uma ampla rede de seguridade e proteção social, entendida como um direito humano, bem como de políticas públicas que garantam formas de trabalho decentes.

Trata-se de um discurso que já havia sido defendido durante a Rio 92, no qual os movimentos da sociedade civil protagonizam as mudanças. A Declaração Final da Cúpula dos Povos possui um tom de luta, bastante usual do radicalismo verde, conforme expressam as suas palavras finais:

"Voltemos aos nossos territórios, regiões e países animados para construirmos as convergências necessárias para seguirmos em luta, resistindo e avançando contra o sistema capitalista e suas velhas e renovadas formas de reprodução. Em pé continuamos em luta!" (CÚPULA DOS POVOS, 2012, p.5)

\section{Quadro 10}

\section{Análise do discurso da Cúpula dos Povos}

\begin{tabular}{|c|c|c|c|}
\hline Ontologia & Relações naturais & Agentes e motivações & Metáforas \\
\hline $\begin{array}{l}\text { O discurso da Cúpula dos } \\
\text { Povos sugere uma mudança } \\
\text { ontológica, que saia da } \\
\text { perspectiva realista - os } \\
\text { recursos naturais como } \\
\text { inputs do processo produtivo } \\
\text { capitalista - para uma } \\
\text { perspectiva nominalista - os }\end{array}$ & $\begin{array}{l}\text { Defende relações de } \\
\text { cooperação e a } \\
\text { convergência entre as } \\
\text { diversas agendas } \\
\text { defendidas pelos } \\
\text { movimentos sociais. } \\
\text { Ao mesmo tempo, }\end{array}$ & $\begin{array}{l}\text { Os agentes de mudança são os } \\
\text { movimentos sociais e } \\
\text { populares, os sindicatos, os } \\
\text { povos, as organizações da } \\
\text { sociedade civil e os } \\
\text { ambientalistas de todo o } \\
\text { mundo. }\end{array}$ & $\begin{array}{l}\text { Lutas pelo } \\
\text { estabelecimento } \\
\text { de uma nova } \\
\text { ordem }\end{array}$ \\
\hline
\end{tabular}




\begin{tabular}{|c|c|c|c|}
\hline \multicolumn{1}{|c|}{ Continuação do quadro 10} \\
$\begin{array}{c}\text { recursos naturais como } \\
\text { direitos da humanidade, a } \\
\text { serem protegidos e } \\
\text { preservados por todos. }\end{array}$ & $\begin{array}{c}\text { estabelecem uma relação } \\
\text { de oposição às grandes } \\
\text { corporações e de } \\
\text { desconfiança em relação } \\
\text { ao Estado. }\end{array}$ & $\begin{array}{c}\text { No entanto, deixa o papel dos } \\
\text { Estados em um segundo plano, } \\
\text { pois considera que os entes } \\
\text { governamentais foram } \\
\text { capturados por interesses do } \\
\text { sistema capitalista. }\end{array}$ \\
\hline
\end{tabular}

Fonte: Elaboração dos Autores

\section{O desenvolvimento sustentável e seus agentes}

Outras importantes discussões aconteceram na Cúpula dos Prefeitos e a Cúpula das Mulheres Chefes de Estado. A cúpula dos Prefeitos, formada pelos 58 prefeitos das maiores cidades do mundo, integrantes do grupo C40, reuniu-se para discutir mudanças climáticas. Nesse discurso, o elemento que se destaca são os agentes: os prefeitos são vistos como os atores com a maior possibilidade de atuar em favor do desenvolvimento sustentável, conforme destaca Rodrigo Rosa, coordenador da Cúpula dos Prefeitos (ROSA, 2012). Para Rosa, a atuação dos prefeitos possibilita mudanças em nível local, mais direcionadas a atender às demandas da sociedade e mais propensas a obter resultados factíveis, impulsionando mudanças também na agenda política.

Nessa cúpula, os prefeitos das maiores cidades do mundo atuaram como protagonistas e se comprometeram a reduzir as emissões de gases de efeito estufa em $12 \%$ até 2016 e em 1,3 bilhão de toneladas até 2030 . Além disso, foi acordada a criação do primeiro Banco de Investimentos Verdes do mundo, o qual terá como objetivo financiar empreendimentos de infraestrutura com baixa emissão de carbono.

A "Cúpula das Mulheres Chefes de Estado pelo Futuro que as Mulheres Querem" enfocou o papel da mulher como protagonista de mudanças da sociedade com relação ao meio ambiente. No discurso proferido pela presidente Dilma, as mulheres foram colocadas como a face da pobreza no mundo, juntamente com as crianças. Ao mesmo tempo, são elas as grandes aliadas no combate à pobreza, pois investem nas crianças, nas famílias e nas comunidades. Elas representam padrões de comportamento, guias de conduta e, por isso, são agentes decisivas nas mudanças nos padrões de consumo, no uso de energia, no uso da água e do solo. Dessa forma, a Cúpula posiciona-se no sentido de defender a promoção da igualdade de gênero e do empoderamento das mulheres no desenvolvimento sustentável.

\section{Perspectivas para as Políticas Públicas Ambientais pós Rio +20}

A análise comparada do discurso do documento "The Future We Want" com os discursos ambientais prévios demonstra que ele busca harmonizar os princípios do desenvolvimento sustentável com aplicação de medidas concretas defendidas pelo racionalismo econômico. Assim, haveria uma tendência de mudança em direção ao estabelecimento de mercado, preços e competição na área ambiental. Assim, devem ser introduzidas políticas ambientais e mudanças regulatórias que modifiquem os preços relativos do uso dos recursos (e.g. mercado de carbono e serviços ecossistêmicos), internalizem os custos das externalidades ambientais e eliminem subsídios aos combustíveis fósseis.

A implementação da economia verde tende a ser prioridade para as Nações Unidas (UNITED NATIONS, 2012, parag. 56-74), que procurará estimular os países a combinarem seus financiamentos, tecnologias, capacitação na direção de encontrar modelos e metodologias para políticas de energias renováveis e para aumentar a criação de empregos ligados à economia verde, como o turismo ambiental (idem, 2012, 
parag.130-131), transporte e cidades sustentáveis ( idem, parag.132-137), tratamento de resíduos (idem, parag. 213-223).

Outro efeito da Rio +20 pode ser a melhoria da comparabilidade e benchmarking das estatísticas ambientais e a criação de metas mundiais, os Objetivos do Desenvolvimento Sustentável (ODS), para que os países priorizem e informem suas ações de proteção do meio ambiente (UNITED NATIONS, 2012, parag. 245251). Para tanto, podemos esperar o fortalecimento de organizações internacionais ambientais, como o Programa das Nações Unidas para o Meio Ambiente (PNUMA), por meio de maior financiamento, tecnologia e capacitação (UNITED NATIONS, 2012, parag. 252-277). Apesar do fortalecimento, o veto à transformação do PNUMA em agência impediu a criação de uma estrutura internacional com poderes para efetivar medidas práticas para proteção ambiental.

Estes avanços dependerão do quanto os países estão dispostos a investir nessas áreas. Durante todo o processo, Estados e empresas tentaram blindar-se contra propostas onerosas, principalmente aquelas que abordaram questões de direitos humanos e responsabilidades ambientais. Esta foi precisamente a grande decepção da Rio +20, o documento final teve um conteúdo bastante minimalista na atribuição de responsabilidades futuras e seu financiamento.

\section{Referências}

BECKER, B. O que causa a perda da biodiversidade é a estrutura econômica que aí está. Entrevista concedida a Rogério Benemond. Desafios do Desenvolvimento: Revista do IPEA, Ano 9, n.71, p.10-16, 2012.

CARVALHO, J.; MACHADO, M.; MEIRELLES, A. Implicações na gestão estratégica de empresas do setor siderúrgico de Minas Gerais. Cad. EBAPE.BR, v. 9, n. 2, p. 220-240, Jun. 2011.

COMIN, F. Economia Verde como orientadora da Rio+20 empobreceu evento. Ecodesenvolvimento, São Paulo, 19 de Julho de 2012. Entrevista concedida a Lilian Neves e Amanda Pinheiro. Disponível em http://www.ecodesenvolvimento.org/posts/2012/julho/a-economia-verde-como-orientadora-da-rio-20? Acesso em 20 de Julho de 2012.

CÚPUla DOS POVOS. Declaração Final da Cúpula dos Povos. Rio de Janeiro, 20-22 de Junho, 2012.

DRYZEK, J. The Politics of the Earth: environmental discourses. New York: Oxford University Press, 1997.

FOUCAULT, M. Power/Knowledge: Selected Interviews and Other Writings, 1972-1977. Brighton: Harvester, 1980.

HABERMAS, J. On the Pragmatics of Communication. Cambridge, Polity Press, 1998.

HALL, P.; SOSKICE, D. Varieties of Capitalism: The Institutional Foundations of Comparative Advantage. Oxford: Oxford University Press, 2001.

HARDIN, G. The Tragedy of the Commons. Science, v. 162, p. 1243-1248, 1968.

LOVELOCK, J. Gaia: alerta final. Rio de Janeiro: Editora Intrínseca Ltda., 2010.

MARCH, J. Como as Decisões Realmente Acontecem: Princípios de Tomada de Decisões. São Paulo: Editora Leopardo, 2010.

MEADOWS, D.; RANDERS, J.; BEHRENS, W. The Limits to Growth. New York: Universe Books, 1972.

MEIRELLES, D. Teorias de mercado e regulação: por que os mercados e o governo falham? Cad. EBAPE. BR, v. 8 , n. 4, p. 644-660, Dez. 2010. 
ROSA, R. Cúpula de prefeitos discute mudanças climáticas na RIO + 20. Zero Hora, Rio de Janeiro, 18 de junho 2012. Entrevista concedida a Lara Ely. Disponível em: http://zerohora.clicrbs.com.br/rs/geral/noticia/2012/06/cupulade-prefeitos-discute-mudancas-climaticas-na-rio-20-3793980.html. Acesso em: 14/07/2012.

SKOPOL, T. "Bringing the state back in: strategies of analysis in current research". In: Evans, P.; Ruesschmeyer, D. e Skocpol, T. (Org.) Bringing the state back in. Cambridge: Cambridge University Press, 1985.

UNITED NATIONS. United Nations Conference on the Human Environment. Stockholm, Sweden, June 5-16, 1972.

Our Common Future: Report of the World Commission on Environment and Development. New York, United States of America, August, 1987.

The Future We Want: Outcome of the United Nations Conference on Sustainable Development. Rio de Janeiro, Brazil, June 20-22, 2012. 